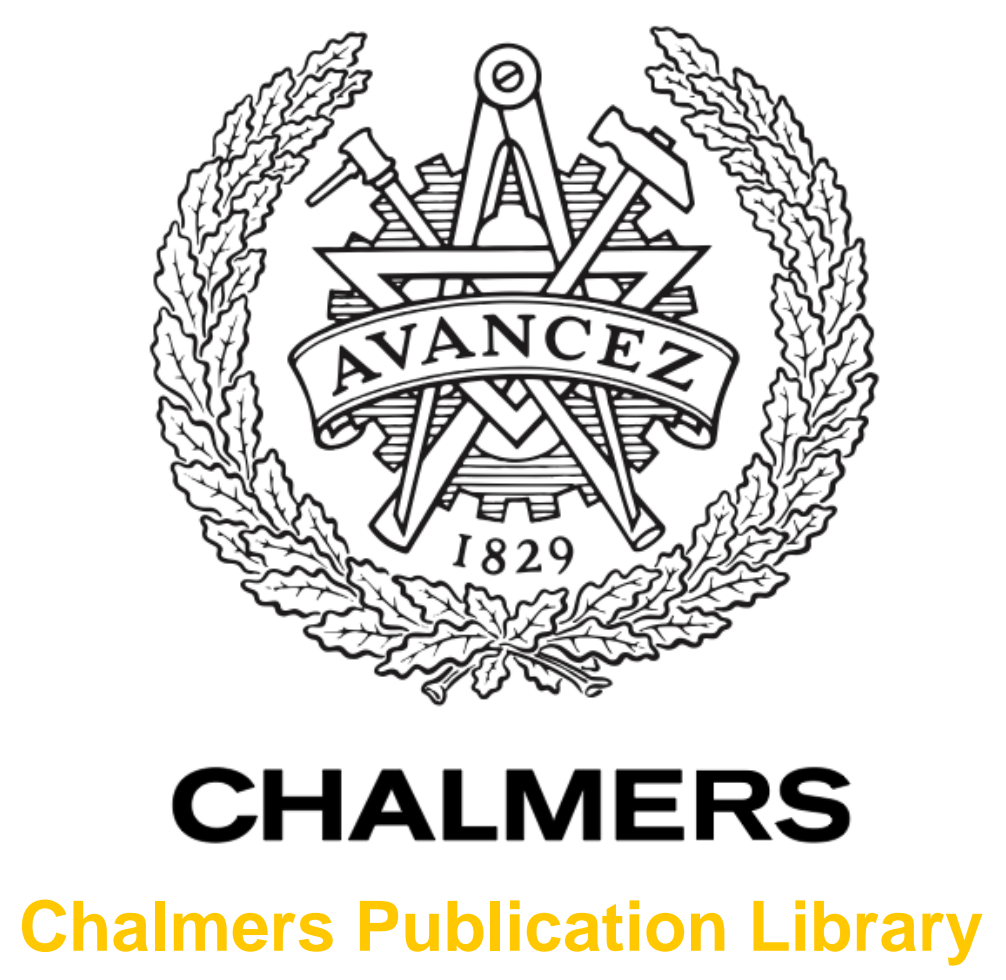

\title{
The Effect of Wind Power Integration on the Frequency of Tap Changes of a Substation Transformer
}

This document has been downloaded from Chalmers Publication Library (CPL). It is the author's version of a work that was accepted for publication in:

IEEE Transactions on Power Systems (ISSN: 0885-8950)

Citation for the published paper:

Shemsedin, N. ; Chen, P. ; Carlson, O. (2013) "The Effect of Wind Power Integration on the Frequency of Tap Changes of a Substation Transformer". IEEE Transactions on Power Systems, vol. 28(4), pp. 4320 - 4327.

http://dx.doi.org/10.1109/TPWRS.2013.2266260

Downloaded from: http://publications.lib.chalmers.se/publication/180512

Notice: Changes introduced as a result of publishing processes such as copy-editing and formatting may not be reflected in this document. For a definitive version of this work, please refer to the published source. Please note that access to the published version might require a subscription.

Chalmers Publication Library (CPL) offers the possibility of retrieving research publications produced at Chalmers University of Technology. It covers all types of publications: articles, dissertations, licentiate theses, masters theses, conference papers, reports etc. Since 2006 it is the official tool for Chalmers official publication statistics. To ensure that Chalmers research results are disseminated as widely as possible, an Open Access Policy has been adopted.

The CPL service is administrated and maintained by Chalmers Library. 


\title{
The Effect of Wind Power Integration on the Frequency of Tap Changes of a Substation Transformer
}

\author{
S. Nursebo, P. Chen, member, IEEE, and O. Carlson
}

\begin{abstract}
As the capacity of wind power installed in a radial distribution system (DS) increases, there is a concern that it may introduce more frequent tap change operations in substation transformers. The increase in the frequency of tap changes (FTC) can accelerate the wear and tear of the tap changers. As a result, the introduction of wind power to DSs may be hindered. Hence the aim of this paper is to investigate the effect of wind power integration on the FTC in a radial DS. A case study shows that the changes on the FTC in DSs connected to relatively strong external grid is negligible up to significant level of penetration. But in DSs connected to a relatively weak external grid, a significant increase in the FTC has been observed as wind power penetration increases. Hence a further investigation is carried out to limit the FTC by using reactive power from local wind turbines. The results have shown that the methodology is very effective.
\end{abstract}

Index Terms-wind power, tap changer, reactive power, load flow analysis, power transformers

\section{NOMENCLATURE}

$b_{k, j} \quad$ series susceptance between bus $k$ and bus $j$

$b_{k, j}^{c} \quad$ shunt susceptance between bus $k$ and bus $j$

$g_{k, j} \quad$ series conductance between bus $k$ and bus $j$

$I \quad$ a set containing all buses in the network

$i \in I$

$u \quad \in I$

$J \quad$ the set of all buses excluding the buses connected to the tap side of a transformer

$j \in J$

$K \quad$ the set of all buses excluding the buses connected to the non-tap side of the transformer

$k \in K$

$n_{k, j, t} \quad$ tap ratio of the transformer between bus $k$ and bus $j$ at time $t$

$n_{k, j}^{\max }$ the maximum tap ratio of the tap changer

$n_{k, j}^{\text {min }} \quad$ the minimum tap ratio of the tap changer

$P_{2, t} \quad$ active power consumed at node ' 2 '

$Q_{2, t} \quad$ reactive power consumed at node ' 2 '

$P_{i, t} \quad$ active power produced at bus $i$ and time $t$

$P_{i, t}^{\mathrm{D}} \quad$ active power consumed at bus $i$ and time $t$

$P_{i, t}^{\max }$ maximum value of active power production at bus $i$ and time $t$
$P_{i, t}^{\min }$ minimum value of active power production at bus $i$ and time $t$

$P_{k, j, t}^{\mathrm{F}} \quad$ active power flow from bus $k$ to bus $j$ at time $t$

$Q_{i, t} \quad$ reactive power produced at bus $i$ and time $t$

$Q_{i, t}^{\mathrm{D}} \quad$ reactive power consumed at bus $i$ and time $t$

$Q_{i, t}^{\max }$ maximum available values of reactive power at bus $i$ and time $t$

$Q_{i, t}^{\min } \quad$ minimum available values of reactive power at bus $i$ and time $t$

$Q_{k, j, t}^{\mathrm{F}} \quad$ reactive power flow from bus $k$ to bus $j$ at time $t$

$R \quad$ resistance between node ' 1 ' and ' 2 '

$X \quad$ reactance between node ' 1 ' and ' 2 '

$S_{i}^{\max } \quad$ The maximum MVA output capability of the wind turbine at bus $i$

$t \quad$ time index

$V_{i, t} \quad$ voltage magnitude at node $i$ and time $t$

$V_{i}^{\max }$ the maximum voltage limit of the tap changer

$V_{i}^{\min }$ the minimum voltage limit of the tap changer

$W_{k, j, t}$ the change in the tap position from $t-1$ to $t$ between bus $k$ and bus $j$

$W_{k, j, t}^{\prime}$ the continuous substitute of the integer variable $W_{k, j, t}$

$Y_{i, u} \quad$ magnitude of the $(i, u)^{t h}$ element of the bus admittance matrix

$y_{i, u} \quad$ series admittance between bus $i$ and bus $u$

$\delta_{i, t} \quad$ voltage angle at node $i$ and time $t$

$\Delta U_{t} \quad$ voltage difference between reference node ' 1 ', $U_{1, t}$ and node ' 2 ', $U_{2, t}$

$\Delta V \quad$ voltage change in per unit value for one tap step

$\Delta V^{d b}$ the deadband voltage magnitude in per unit

$\varepsilon \quad$ a very low value chosen based on the sensitivity of the tap operating system

$\Phi^{\text {min }} \quad$ allowed minimum power factor

$\varphi_{k, j} \quad$ angle of the series admittance between bus $k$ and bus $j$

$\theta_{i, u} \quad$ angle of the $(i, u)^{t h}$ element of the bus admittance matrix

\section{INTRODUCTION}

This work was financed by Chalmers energy initiative.

S. Nursebo is with Chalmers University of Technology, Sweden (email: Shemsedin.nursebo@chalmers.se).

P. Chen is with Chalmers University of Technology, Sweden (email: peiyuan@chalmers.se).

O. Carlson is with Chalmers University of Technology, Sweden (email: Ola.carlson@chalmers.se).

\section{$\mathbf{T}$} RANSFORMERS are the most critical components of a distribution system (DS). Since they are capital intensive, only few transformers supply power to a large number of customers in a given DS. Hence high availability of these components is given utmost importance by any given DSO. 
The failure of a transformer, besides jeopardizing the reliability of the DS, will expose the DSO to a huge amount of cost. The causes of transformer failure are numerous [1]-[6]. However the majority of transformer failures can be traced back to a faulty tap changer [4]-[7]. Hence, in terms of the reliability of the transformer, tap changers can be considered as the critical part of the transformer. This is evident from the extensive literature that is devoted for condition monitoring and maintenance of tap changers [6]-[13].

The main reasons for the failure of tap changers are the erosion of the diverters contact due to switching arcs, the wear and tear of the mechanical components such as the energy accumulator springs, carbon formation in the diverter oil caused by arcing, and breakdown of the insulating materials due to accumulation of sludge. Among these the first three directly relate to the number of tap operations that occurred in the tap changer. Especially the wear in the diverter contacts depends not only on the number of tap changes but also on the transformer load during the tap change [13].

With the increased introduction of wind power in DSs, some DSOs are concerned about its possible effect on the wear and tear of the tap changers. This concern mainly arises from a fluctuating nature of wind power as well as the possible increase in the power flow through the transformer. The fluctuating power output from the wind turbines can introduce high power flow fluctuation through the transformer. This may ultimately lead to an increase in frequency of tap changes. If this is the case, considering the power system is already vulnerable to wear and tear due to aging, the DSO may limit the integration of wind power to its network for fear of increased maintenance costs or unexpected tap changer failures. Hence, such concerns may hinder the integration of renewable energy sources at a time governments are working to increase the share of these energy sources.

However the investigation of the effect of wind power integration on the frequency of tap changes (FTC) is given only a minor attention. There are only a few papers, to the authors' knowledge, that have given some focus to FTC in the presence of wind power [14]-[17].

In [14]-[16] the aim is on how to better regulate the voltage of a DS in the presence of wind power. Some focus is given to the effect of different voltage regulation approaches on the FTC. However, these papers have not investigated the effect of wind power introduction on the FTC.

Thus, it is only [17] that have analyzed the effect of wind power variability on the FTC. The analysis is done for wind turbines installed in meshed sub-transmission system. From the result of the analysis, it is concluded that, in general, wind power injection increases the FTC. The increase is found to be significant when the wind turbines are involved in voltage regulation.

In [17] the change in the FTC due to wind power is analyzed based on only one month data. However we have observed in our analysis that wind power can increase the FTC in one month and decrease in the other. Hence an analysis based on one month data cannot give the full picture of the effect of wind power on the FTC. In addition, as we can see later, the effect of wind power on the FTC also depends on the grid strength. However this has not been presented before. Moreover, the use of reactive power compensation to reduce the FTC is not investigated either.

Thus this paper tries to fill the gap in this area. A detailed analysis of the effect of wind power integration on the FTC is carried out based on one year measured wind power and load data obtained from a DSO in Sweden. Moreover, most variable speed wind turbines have the capability to provide a considerable amount of controllable reactive power support. Thus, a further investigation is carried out to use this readily available reactive power from the wind turbines to decrease the FTC, wherever there is the need to do so. Such investigation is valuable because, as mentioned above, tap changers are exposed to wear depending on the number of operation they have undergone. Moreover reactive power can provide a better voltage regulation at secondary side of the transformer since, unlike tap changer, it does not have a time delay in operation.

This paper is organized as follows. In Section II, the problem is formulated mathematically. Section III provides the results from the case study where the effect of wind power on the FTC is discussed in detail. It also investigates the possibility of using reactive power from the wind turbines to decrease the FTC. Finally Section IV provides the conclusion of the paper.

\section{PROBLEM Formulation}

This section has two subsections. The first subsection presents the mathematical model that can be used to determine the number of tap changes in a given distribution. The model uses network, load and wind power data as an input. The next subsection develops the model further to incorporate reactive power compensation (RPC) as a means to reduce the FTC.

\section{A. Model set up for analyzing the effect of wind power on frequency of tap changes}

To analyze the effect of wind power on the FTC one has to determine the FTC with and without wind power. Thus, a mathematical model is needed to determine the FTC in each case. Such a model can be used to carry out a series of load flow calculations using the network, load and wind power data as inputs. The main aim of these load flow calculations is determining the tap position at each time step satisfying the different equality and inequality constraints.

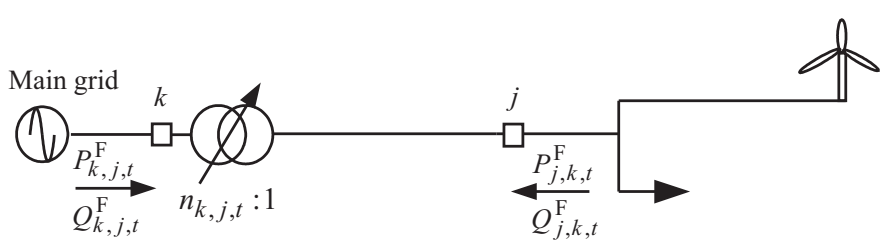

Fig. 1: A simple distribution network with wind power and load connected.

During a load flow calculation at time step $t$, the difference between the tap ratios $n_{k, j, t}$ and $n_{k, j, t-1}$ needs to be as small as possible (see Fig. 1). Let this difference be the tap step taken at time $\mathrm{t}$ i.e. $W_{k, j, t}$. Thus the load flow calculation at each time 
step, $t$, can be formulated as an optimization problem with the objective function to minimize the number of tap changes at each time step $t$ :

$$
\min _{W} O_{t}:=\sum_{k} \sum_{j} W_{k, j, t}^{2}
$$

Subject to equality and inequality constraints described as follows.

1) The inequality constraints: The inequality constraints include the limit on secondary side voltage of the transformer,

$$
V_{i}^{\min } \leq V_{i, t} \leq V_{i}^{\max }
$$

the limit on the available range of tap ratio,

$$
n_{k, j}^{\min } \leq n_{k, j, t} \leq n_{k, j}^{\max }
$$

and the limit on the available active and reactive power of generators at each node in the network

$$
\begin{aligned}
& P_{i, t}^{\min } \leq P_{i, t} \leq P_{i, t}^{\max } \\
& Q_{i, t}^{\min } \leq Q_{i, t} \leq Q_{i, t}^{\max }
\end{aligned}
$$

In the case study, it is only at the slack bus (infinite grid) that the active and reactive power is produced. Hence $P_{j, t}$ and $Q_{j, t}$ is limited to zero at all buses except the slack bus. Wind power generation is included into the load flow equations as a negative load with unity power factor.

2) Equality constraints: The equality constraints consist of the load flow equations,

$$
\begin{aligned}
& P_{i, t}-P_{i, t}^{\mathrm{D}}=\sum_{u} Y_{i, u} V_{i, t} V_{u, t} \cos \left(\theta_{i, u}+\delta_{u, t}-\delta_{i, t}\right) \\
& Q_{i, t}-Q_{i, t}^{\mathrm{D}}=-\sum_{u} Y_{i, u} V_{i, t} V_{u, t} \sin \left(\theta_{i, u}+\delta_{u, t}-\delta_{i, t}\right)
\end{aligned}
$$

and

$$
n_{k, j, t}=n_{k, j, t-1}+W_{k, j, t} \Delta V
$$

In the load flow equations the tap ratio of the transformer may change from one time step to another. This changes certain elements of the bus admittance matrix from one time step to another, which increases the number of variables in the model. Clearly, this imposes extra computational burden on the simulation. Hence the load flow equations in (5) are modified so that they do not use the bus admittance matrix directly. The discussion of these modified load flow equations is provided as follows.

3) Modified load flow equations: The link between two buses is usually either a power line or a transformer. The power line can be represented by an equivalent $\pi$-model as shown in Fig. 2.

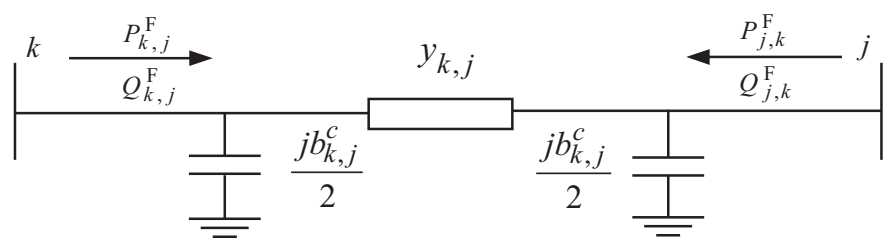

Fig. 2: $\pi$-model of a power line.

A transformer between two buses is represented by the equivalent $\pi$-model shown in Fig. 3

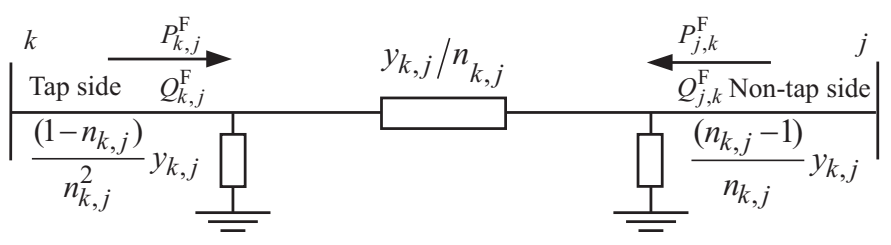

Fig. 3: Equivalent circuit of a tap changing transformer [18].

Hence, for the network which contains both of these elements, i.e. power lines and transformers, the link between any two buses can be represented by the model shown in Fig. 4.

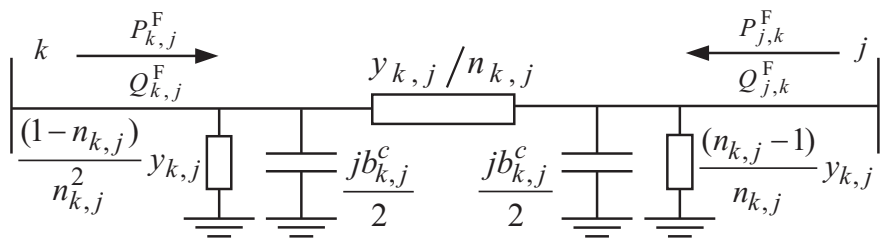

Fig. 4: An equivalent model for a link between any two nodes.

The power flow from bus $k$ to any other bus $j$ at time $t$ is given by:

$$
\begin{aligned}
P_{k, j, t}^{\mathrm{F}} & =\left(\frac{V_{k, t}}{n_{k, j, t}}\right)^{2} g_{k, j}-\frac{V_{k, t} V_{j, t}}{n_{k, j, t}} y_{k, j} \cos \left(\delta_{j, t}-\delta_{k, t}+\varphi_{k, j}\right) \\
Q_{k, j, t}^{\mathrm{F}} & =-V_{k, t}^{2}\left(\frac{b_{k, j}}{n_{k, j, t}^{2}}+\frac{b_{k, j}^{c}}{2}\right)+\frac{V_{k, t} V_{j, t}}{n_{k, j, t}} y_{k, j} \sin \left(\delta_{j, t}-\delta_{k, t}+\varphi_{k, j}\right)
\end{aligned}
$$

and power flow from bus $j$ to any other bus $k$ at time $t$ is given by:

$$
\begin{aligned}
P_{j, k, t}^{\mathrm{F}} & =V_{j, t}^{2} g_{j, k}-\frac{V_{j, t} V_{k, t}}{n_{k, j, t}} y_{j, k} \cos \left(\delta_{k, t}-\delta_{j, t}+\varphi_{k, j}\right) \\
Q_{j, k, t}^{\mathrm{F}} & =-V_{j, t}^{2}\left(b_{j, k}+\frac{b_{j, k}^{c}}{2}\right)+\frac{V_{j, t} V_{k, t}}{n_{k, j, t}} y_{j, k} \sin \left(\delta_{k, t}-\delta_{j, t}+\varphi_{k, j}\right)
\end{aligned}
$$

In (7) and (8), if the link between two buses is a cable or overhead line, the tap ratio is one and the equations will represent the power flow in the circuit shown in Fig. 2. On the other hand, if the link between two buses is a transformer the shunt capacitance is equal to zero. Then (7) and (8) represent the power flow in the circuit shown in Fig. 3.

Now the load flow equations in (5) are replaced by (9) and (10) below as equality constraints.

For bus in $k \in K$ :

$$
\begin{aligned}
& P_{k, t}-P_{k, t}^{\mathrm{D}}=\sum_{j} P_{k, j, t}^{\mathrm{F}} \\
& Q_{k, t}-Q_{k, t}^{\mathrm{D}}=\sum_{j} Q_{k, j, t}^{\mathrm{F}}
\end{aligned}
$$

For bus $j \in J$ :

$$
\begin{aligned}
& P_{j, t}-P_{j, t}^{\mathrm{D}}=\sum_{k} P_{j, k, t}^{\mathrm{F}} \\
& Q_{j, t}-Q_{j, t}^{\mathrm{D}}=\sum_{k} Q_{j, k, t}^{\mathrm{F}}
\end{aligned}
$$

Equations (7) - (10) do not contain the variable bus admittance matrix. In other words, there is no need to recalculate admittance matrix any more. This leads to a reduction in the number of decision variables in the optimization model. 
B. Modeling the use of RPC to decrease the frequency of tap changes

In this section we develop the model for analyzing the use of reactive power from the wind turbines to decrease the FTC.

1) The objective function: When there is a continuously controllable reactive power from wind turbines, it can be used to decrease the FTC. In principle, reactive power is consumed to avoid a tap increase during low load condition and produced to avoid a tap decrease during high load condition. However reactive power is not consumed or produced when there is no potential tap change or the available reactive power is not sufficient to prevent a tap change. In the latter case, it is better to use tap regulation directly as unnecessary reactive power flow increases system power losses. In order to model this, the objective function is modified as follows:

$$
\min _{W, Q} O_{t}:=\sum_{k} \sum_{j} a W_{k, j, t}^{2}+\sum_{i} Q_{i, t}^{2}
$$

The term on the far right side is added to produce or consume as minimum amount of reactive power as possible from the wind turbines. On the other hand $a$ is a constant of sufficiently large value added to prioritize using RPC, whenever possible, instead of tap changing. In our analysis, selecting the value of $a$ to be above 1000 gives the required result.

2) The constraints: The equality constraints discussed in (6), (9), (10) and the inequality constraints discussed in (2), (3) hold true here as well.

The reactive power limits, $Q_{i, t}^{\min }$ and $Q_{i, t}^{\max }$ in (4), can be defined in terms of a given minimum operating power factor limit, $\Phi^{\mathrm{min}}$. These limits can also be constrained by the thermal capability of the wind turbine, $S_{i}^{\max }$. This happens when the wind turbines are operating around the rated power output. Hence for a given wind turbine at bus $i$, the reactive power limits are given by (12) and (13).

$$
-Q_{i, t}^{\mathrm{cap}} \leq Q_{i, t} \leq Q_{i, t}^{\mathrm{cap}}
$$

where

$$
Q_{i, t}^{\mathrm{cap}}=\min \left(\sqrt{\left(S_{i}^{\max }\right)^{2}-P_{i, t}^{2}}, \frac{P_{i, t} \sqrt{\left(1-\left(\Phi^{\mathrm{min}}\right)^{2}\right)}}{\Phi^{\min }}\right)
$$

In case $\Phi^{\text {min }}$ is extended to zero, i.e. when the wind turbines are providing reactive power support even when they are not producing active power, (12) and (13) can be reduced to (14).

$$
-\sqrt{\left(S_{i}^{\max }\right)^{2}-P_{i, t}^{2}} \leq Q_{i, t} \leq \sqrt{\left(S_{i}^{\max }\right)^{2}-P_{i, t}^{2}}
$$

\section{The flow chart of the proposed sequential load flow simu- lation}

The model formulated in this paper is to be used in radial DS where there are usually one or two transformers in parallel. Under such condition the binary variable, $W_{k, j, t}$, can be replaced by a continuous variable, $W_{k, j, t}^{\prime}$, and (15) can be used to calculate $W_{k, j, t}$. This results in a model which can be solved more efficiently using solvers developed for nonlinear programs, e.g. [19]. However whenever this model is used in networks where there are a couple of tap changing transformers at different locations there could be an optimality problem. Hence under such situation the problem should be solved as mixed integer nonlinear programming model (MINLP).

$$
W_{k, j, t}=\left\{\begin{array}{ccc}
\operatorname{round}\left(W_{k, j, t}^{\prime}\right), & \text { if } & \left|W_{k, j, t}^{\prime}\right| \leq \varepsilon \\
\operatorname{ceil}\left(W_{k, j, t}^{\prime}\right), & \text { if } & W_{k, j, t}^{\prime}>\varepsilon \\
\operatorname{floor}\left(W_{k, j, t}^{\prime}\right), & \text { if } & W_{k, j, t}^{\prime}<-\varepsilon
\end{array}\right.
$$

The flow chart of the overall simulation is presented in Fig. 5.

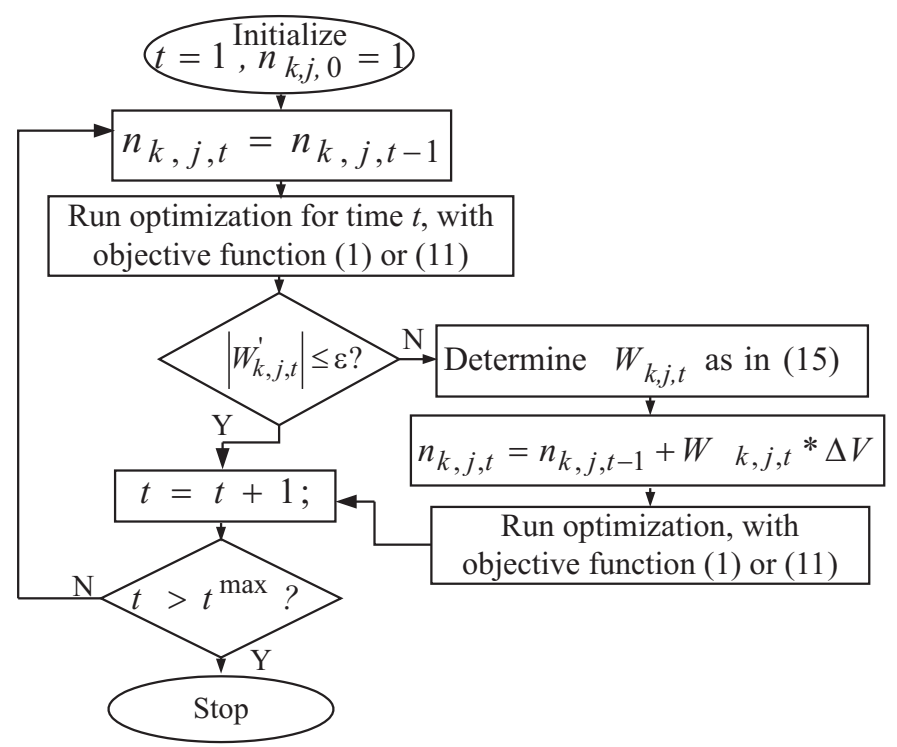

Fig. 5: The flow chart of the proposed sequential load flow simulation.

\section{CASE Study}

\section{A. Network and data description}

The case study is based on a rural $11 \mathrm{kV}$ network operated by Falbygdens Energi located in Falköping area in Sweden. The network is fed by a $40 \mathrm{kV}$ grid through a 10 MVA $45 \pm 8 \times 1.67 \% / 11.5 \mathrm{kV}$ transformer with percentage impedance of $8 \%$. The tap changer regulates the voltage at the secondary side of the transformer with the set point voltage of $10.7 \mathrm{kV}$ and $\pm 1.2 \%$ deadband. In this DS, there are 13 wind turbines installed, with an overall installed capacity of $12.225 \mathrm{MW}$. From these wind turbines there are hourly measured time series data available for one year in 2011. Hourly measured active and reactive power data at the substation are also available for the same year. Active power consumption in the network is then calculated by adding the measured wind power data and active power measurement at the substation. Currently the wind turbines operate at unity power factor (PF) setting, thus the reactive power is assumed to come from consumer loads only. Thus the wind power and load data so obtained have been used in the load flow analyses done in this paper.

\section{B. Effect of wind power on frequency of tap changes}

The aim here is to find out if wind power can contribute to an increase in the FTC. Thus no reactive power compensation from the wind turbines is considered. 
With the data described in the above subsection, the mathematical model developed in Section II is implemented in GAMS. Two cases are investigated:

- Case 1: only consumer load is assumed to be connected to the network without wind power in the system.

- Case 2: both load and wind power are connected to the system. This is the existing system condition.

Fig. 6 shows the number of tap changes at each hour of a day summed over one year. It can be seen from Fig. 6 that

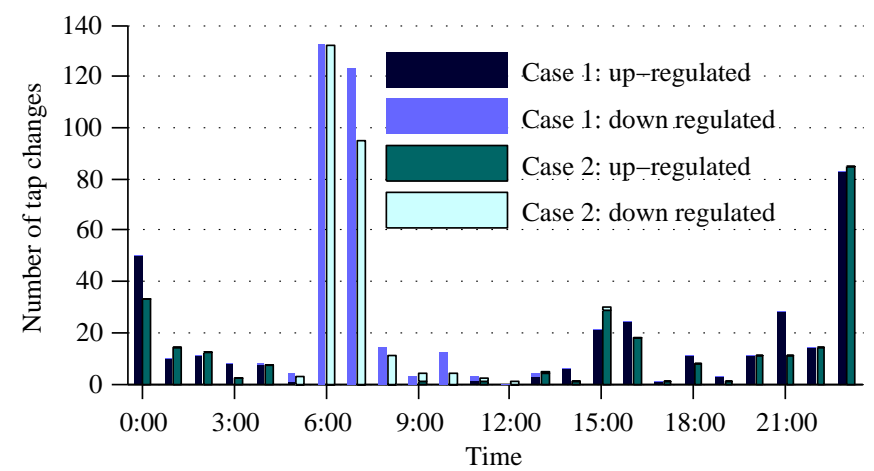

Fig. 6: Number of tap changes on each hour of a day summed over a year.

for both cases, the diurnal variation of tap changes follows a similar trend: with a large number of tap changes at 6:00 and 7:00 in the morning and at 23:00 and 0:00 during the night. There are also considerable tap changes at 15:00 and 16:00.

Usually the tap changes in the morning (specifically between 5:00 and 10:00) are down regulations to boost the voltage on the secondary side. During this period, the load increases due to the startup of a factory, connected to this DS, and residential loads. During the rest of the day, the tap is usually up-regulated due to the dominance of lighter load conditions than in the morning.

The total number of tap changes for Case 1 is 585 and for Case 2 is 505. Thus, contrary to our expectation, the FTC has decreased when there is wind power in the DS. The reason for the decrease in number of tap changes is explained using Fig. 7 and Fig. 8.

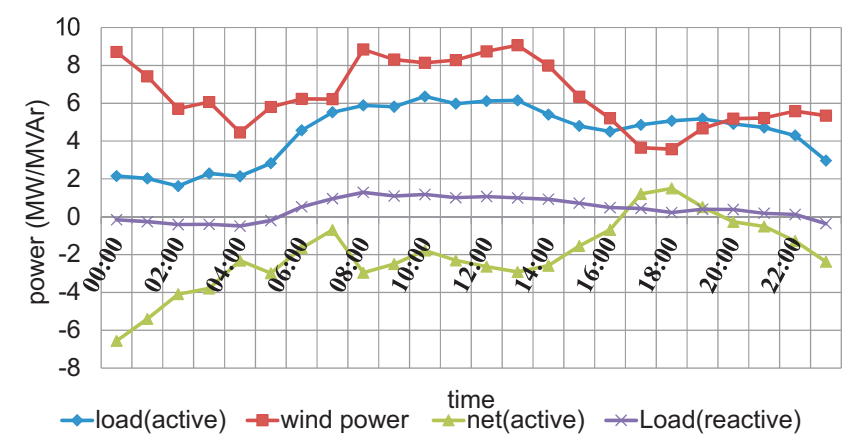

Fig. 7: Load and wind power profile at specific day of the year.

Fig. 7 shows the load and wind power profile for a specific day and Fig. 8 shows the tap positions of the tap changer in the same day. It can be seen in Fig. 8, between the period 5:00

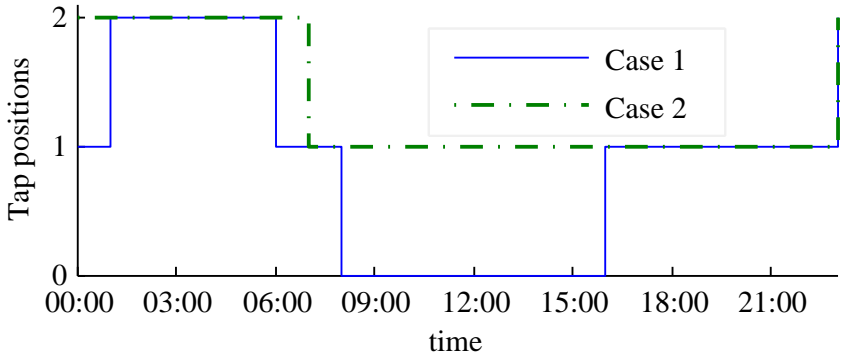

Fig. 8: Tap position of the tap changer at specific day of the year.

and 16:00, there are three tap changes in Case 1 compared to a single tap change in Case 2 (see Fig. 8). From Fig. 7, one can make two observations. On one hand, the variability of load follows the variability of wind power. These results in a less variable net active power. On the other hand, during part of this period (for example between 14:00 and 20:00) when the net active power increases, the reactive power decreases and vice versa. This, according to (16) ${ }^{1}$ [20], results in lower voltage change on the secondary side of the transformer compared to Case 1.

$$
\Delta U_{t} \approx R P_{2, t}+X Q_{2, t}
$$

Moreover wind power causes fluctuation mostly in active power. Fluctuations in active power, according to (16), will not lead to a significant voltage fluctuations when the $\mathrm{X} / \mathrm{R}$ ratio of the external grid is high.

In Fig. 7 and Fig. 8, the aim is to show how wind power can contribute to a decrease in the number of tap changes in some days. But wind power do also contribute to an increase in the number of tap changes on some other days. However, in this case, wind power has led to the reduction in the total number of tap changes.

\section{The frequency of tap changes for varying level of wind power and grid strength}

The analysis in the previous section is done assuming the short circuit capacity (SCC) and the X/R ratio of the external grid to be 171 MVA and 10 respectively. For this DS, it is seen that wind power does not pose a significant threat to the FTC. In fact, it may reduce the FTC. In this subsection the same investigation is done for grids with different SCCs and with varying $\mathrm{X} / \mathrm{R}$ ratios.

Fig. 9 shows the trend in FTC as the power penetration level increases for grids with different SCC. The figure shows that, overall, the FTC increases with decrease in SCC. This is understandable as a higher impedance leads to a higher voltage drop for a given loading condition. In other words, for the same variation of transformer loading, the voltage variation will become larger in a weaker grid.

On the other hand, it may incorrectly be concluded from Fig. 9 that wind power contributes to reduction in the FTC.

\footnotetext{
${ }^{1}$ In this equation $R$ and $X$ can be considered the resistance and reactance of the transformer plus the external grid. Hence $\Delta U_{t}$ is the voltage difference between the secondary side of the transformer $U_{2, t}$ and the external grid $U_{1, t}$.
} 


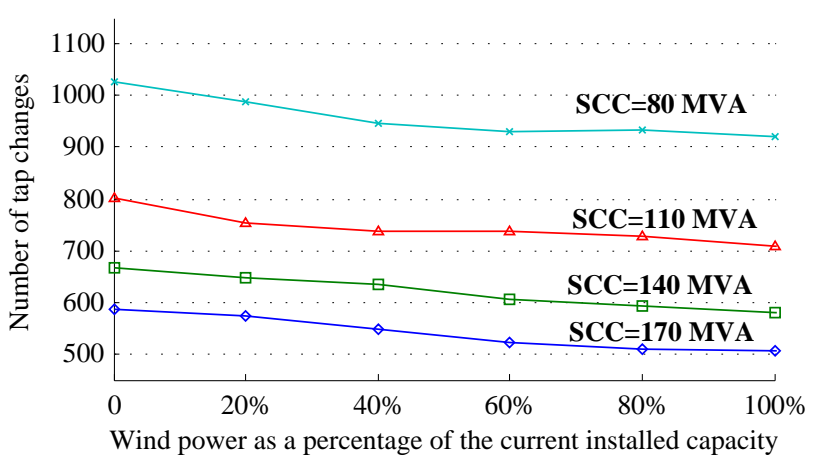

Fig. 9: Number of tap changes per year for different SCC of external grid with $\mathrm{X} / \mathrm{R}=10$.

However that is not always the case. An analysis with a different reference voltage, e.g. $10.8 \mathrm{kV}$, at the secondary side of the transformer has shown a different result. But no significant increase in FTC is observed.

Moreover, the curves in the Fig. 9 show similar profile as the wind power penetration level increases. Multiple other analyses (not shown here) have shown similar results. That is, the overall percentage change in FTC with increasing wind power capacity is roughly the same whenever the SCC is varied while keeping the $\mathrm{X} / \mathrm{R}$ ratio constant. The reasoning for this observation is as follows.

A tap change occurs when there is a voltage change at the secondary side of a transformer due to change in power flow. Hence one can roughly approximate the FTC to be proportional to the voltage change that occurs at each time step $t$ due to power flow changes.

The voltage change that occurred originally ${ }^{2}$ in Fig. 9 due to load flow changes is given by (16). Now due to wind power, there is additional fluctuation in active power $\Delta P_{2, t}$. Hence this fluctuation causes an additional voltage fluctuation $\Delta U_{2, t}$ at the secondary side of the transformer which can be given by (17). The percentage change in voltage change can thus be given by (18). Since the FTC is proportional to the voltage change at the transformer secondary, (19) follows from (18).

$$
\begin{gathered}
\Delta U_{2, t} \approx \Delta P_{2, t} \times R \\
\frac{\Delta U_{2, t}}{\Delta U_{t}}=\frac{\Delta P_{2, t}}{P_{2, t}+Q_{2, t} \times(X / R)} \times 100 \%
\end{gathered}
$$

and

$$
\Delta F T C \propto \frac{\Delta P_{2, t}}{P_{2, t}+Q_{2, t} \times(X / R)} \times 100 \%
$$

Equation (19) implies that the percentage change in FTC is proportional to the $\mathrm{X} / \mathrm{R}$ ratio and is constant for a given $\mathrm{X} / \mathrm{R}$ ratio irrespective of the SCC of the grid. However the tap change does not only depend on the voltage change at the secondary side of the transformer but also whether the resulting voltage will be outside of the deadband. Hence based on (19) one can only roughly expect the implications to hold. Fig. 9 proves the same.

\footnotetext{
${ }^{2}$ when there is no wind power in the system
}

The above analysis shows that for X/R of 10 no significant increase in the FTC is expected due to introduction of wind power operating at unity power factor. Fig. 10 provides the results of the analysis with different $\mathrm{X} / \mathrm{R}$ ratios. The results show that when the $X / R$ ratio gets lower the effect of wind power on the FTC changes becomes considerable. This is clear from (19) that for a given active power change, the lower the $\mathrm{X} / \mathrm{R}$ ratio the bigger is the change in FTC.

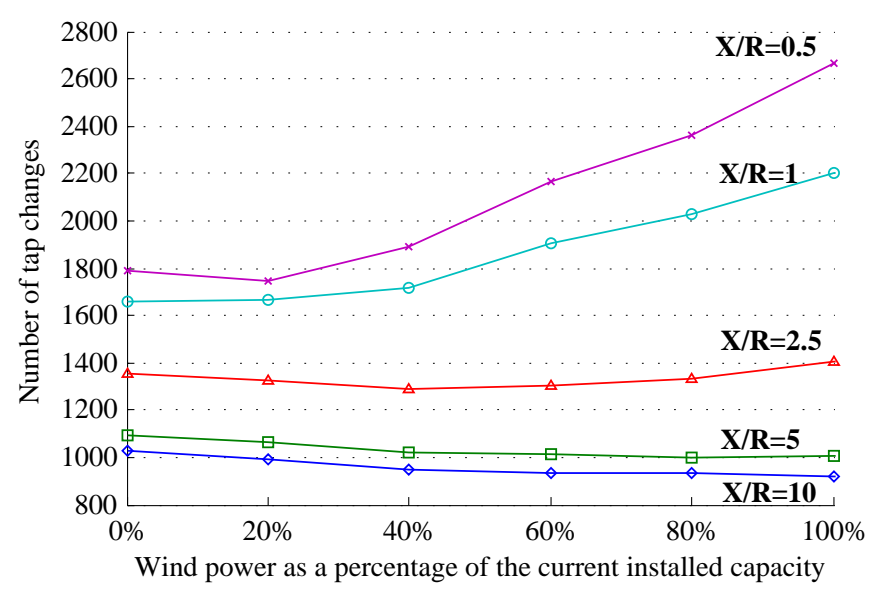

Fig. 10: Number of tap changes per year in a DS connected to 80 MVA external grid having different $\mathrm{X} / \mathrm{R}$ ratio.

Based on the analysis so far and using Fig. 10, it can be concluded that for distribution networks with X/R ratio greater than 5 there is no real danger of increase in FTC due to wind power. But for distribution networks with $\mathrm{X} / \mathrm{R}$ ratio less than 5 , there could be some problems of increase in FTC due to wind power introduction. This is especially true for those grids with $X / R$ ratio less than 2.5 .

Hence, when planning wind power connection, the DSOs of such DSs need to pay attention to the effect of wind power on the tap changers. The DSOs need to find ways to deal with this problem. The current practice is to extend the deadband of the tap changer, say from $1.2 \%$ to $1.6 \%$ or more. However this solution may pose voltage quality problems. In the next subsection we investigate the use of reactive power from the wind turbines to decrease the FTC.

\section{Using reactive power compensation to reduce the number of tap changes}

Among the available wind turbines in the network, a wind farm composed of four $0.8 \mathrm{MW}$ wind turbines is chosen to provide reactive power support to the grid. These wind turbines are variable speed design (full converter based) from Enercon and are recently installed at a site close to the substation. They started production as of March 2011. The wind power from the rest of the wind turbines is aggregated with the load. The simplified diagram of the resulting system is shown in Fig. 11.

The majority of grid codes require that wind turbines should have a capability of operating between $0.95 \mathrm{PF}$ lagging and leading at full production [21]. This indicates that, for these 


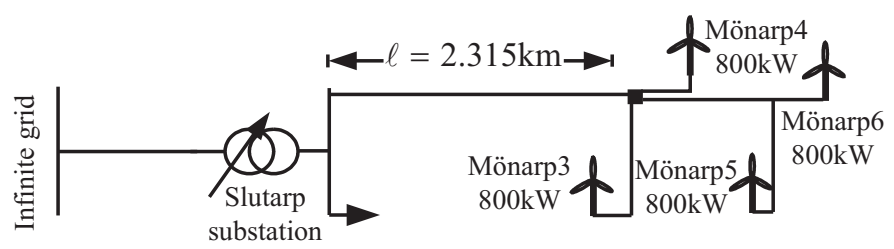

Fig. 11: Simplified diagram of the $10 \mathrm{kV}$ distribution network.

wind turbines, the rated power of the converter should be at least five percent higher than the full power output of the wind turbines. Hence $S_{i}^{\max }$, for each wind turbine, is taken to be five percent higher than the rated power output.

Fig. 12 compares the number of tap changes with and without RPC when the wind turbines are controlled to operate between 0.95 lagging and leading power factor so as to avoid a tap change whenever possible.

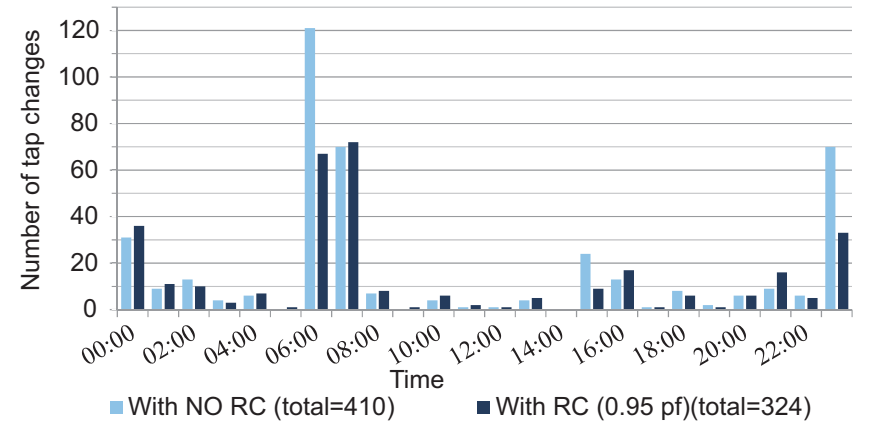

Fig. 12: Number of tap changes on $24 \mathrm{hr}$ basis with and without reactive power compensation.

The figure shows a decrease in the FTC by $21 \%$. From the figure it is clear that RPC can be used to effectively alleviate the voltage regulating stress from the transformer tap changer.

Reactive power is consumed at light load or at windy conditions when there is a potential tap up-regulation. This brings down the voltage at the substation busbar and avoids an up-regulation of the tap. Reactive power is supplied to boost the voltage during high loading condition to avoid a potential tap down-regulation. In this way, reactive power contributes to the reduction in the number of tap changes.

It can be seen that RPC sometimes only delays a tap change to a later time. This is seen in Fig. 12 when the number of tap changes decreases at 23:00 while the number of tap changes increases at 00:00. However, this delay of tap changes does not appear to be a significant issue. Moreover, it could be reduced if accurate load and wind power forecasts are available.

Table I summarizes the main points that can be used in the comparative analysis of using RPC to reduce the FTC. It also includes results from some more scenario analysis. The results in Table I are for a grids with $\mathrm{SCC}=171 \mathrm{MVA}$ and $\mathrm{X} / \mathrm{R}=10$. Table II provides the results of the same analysis for a weaker grid having $\mathrm{SCC}=80 \mathrm{MVA}$ and $\mathrm{X} / \mathrm{R}=1$. Moreover in Table I and II, the wind turbines are located $2.3 \mathrm{~km}$ from the substation. On the other hand, Table III provides the results of the same analysis for wind turbines located $15 \mathrm{~km}$ from the substation. The analysis with longer distance is used to see if the magnitude of the impedance between the wind farm and the substation has some effect on the proposed solution. Over all, the results provided in Table I-III shows that RPC can be used for reducing the FTC in any grid.

TABLE I: Effect of using reactive power compensation to reduce the FTC in a distribution system connected to a stronger grid $(\mathrm{SCC}=171$ MVA, $\mathrm{X} / \mathrm{R}=10$ )

\begin{tabular}{|l|r|r|r|l|l|}
\hline \multirow{2}{*}{ Case } & \multirow{2}{*}{$\Phi^{\text {min }}$} & \multicolumn{2}{|l|}{$\begin{array}{l}\text { Change in the } \\
\text { FTC }(\Delta \text { FTC })\end{array}$} & $\begin{array}{l}\text { Average } \\
\text { power Loss } \\
(\mathbf{k W})\end{array}$ & $\begin{array}{l}\text { Average reactive } \\
\text { power from the wind } \\
\text { turbines (kVAr) }\end{array}$ \\
\cline { 2 - 6 } & & $\Delta$ FTC & $\% \Delta$ FTC & \\
\hline 1 & 1 & 0 & 0 & 16 & 0 \\
\hline 2 & 0.95 & -86 & -21 & 16 & 15 \\
\hline 3 & 0.90 & -124 & -30 & 16 & 25 \\
\hline 4 & 0.80 & -166 & -40 & 16 & 36 \\
\hline 5 & 0 & -410 & -100 & 14 & 176 \\
\hline
\end{tabular}

TABLE II: Effect of using reactive power compensation to reduce the FTC in a distribution system connected to a weaker grid $(\mathrm{SCC}=80$ MVA and $\mathrm{X} / \mathrm{R}=1$ )

\begin{tabular}{|l|r|r|r|l|l|}
\hline \multirow{2}{*}{ Case } & \multirow{2}{*}{$\Phi^{\min }$} & \multicolumn{2}{|l|}{$\begin{array}{l}\text { Change in the } \\
\text { FTC }(\Delta \text { FTC })\end{array}$} & $\begin{array}{l}\text { Average } \\
\text { power Loss } \\
(\mathbf{k W})\end{array}$ & $\begin{array}{l}\text { Average reactive } \\
\text { power from the wind } \\
\text { turbines (kVAr) }\end{array}$ \\
\cline { 3 - 6 } & & $\Delta \mathrm{FTC}$ & $\% \Delta \mathrm{FTC}$ & 0 \\
\hline 1 & 1 & 0 & 0 & 86 & 0 \\
\hline 2 & 0.95 & -394 & -22 & 85 & 33 \\
\hline 3 & 0.90 & -502 & -28 & 85 & 64 \\
\hline 4 & 0.80 & -663 & -37 & 85 & 121 \\
\hline 5 & 0.0 & -1738 & -97 & 91 & 724 \\
\hline
\end{tabular}

TABLE III: Reactive power compensation from wind turbines located $15 \mathrm{~km}$ away from the substation ( $\mathrm{SCC}=171 \mathrm{MVA}, \mathrm{X} / \mathrm{R}=10$ )

\begin{tabular}{|c|c|c|c|c|c|}
\hline \multirow[t]{2}{*}{ Case } & \multirow[t]{2}{*}{$\Phi^{\min }$} & \multicolumn{2}{|c|}{$\begin{array}{l}\text { Change in the } \\
\text { FTC }(\Delta \text { FTC })\end{array}$} & \multirow{2}{*}{$\begin{array}{l}\text { Average } \\
\text { power Loss } \\
(\mathrm{kW})\end{array}$} & \multirow{2}{*}{$\begin{array}{l}\text { Average reactive } \\
\text { power from the wind } \\
\text { turbines }(\mathrm{kVAr})\end{array}$} \\
\hline & & $\Delta \mathrm{FTC}$ & $\% \Delta \mathrm{FTC}$ & & \\
\hline 1 & 1 & 0 & 0 & 28 & 0 \\
\hline 2 & 0.95 & -90 & -22 & 28 & 16 \\
\hline 3 & 0.90 & -120 & -29 & 28 & 25 \\
\hline 4 & 0.80 & -166 & -40 & 28 & 36 \\
\hline 5 & 0.0 & -416 & -100 & 27 & 176 \\
\hline
\end{tabular}

In terms of achieving a specific level of reduction in the FTC, the distance of wind turbines from the substation has no effect at all. That is, almost the same amount of reactive power is necessary to achieve the same level of reduction in the FTC. Thus, the cable does not make any significant impact on the reactive power requirement from the wind turbines.

However, compared to strong grids, in weak grids more reactive power is required from the wind turbines to achieve the same level of reduction in FTC. This is because, in weak grids, higher number of tap changes need to be avoided to achieve the same percentage of reduction in the FTC.

Generally, the change in the network loss relative to the base case (Case 1) is found to be negligible in all cases except in Case 5 of Table II. This is evident from the fact that, in this case, the network resistance is relatively large and the amount of reactive power consumed or produced by the wind turbines relatively high. 
Finally, the analysis presented in this paper is carried out assuming constant power loads however similar results are obtained assuming constant impedance load.

\section{CONCLUSION}

In this paper an analysis of the effect of wind power on the FTC is carried out. In general, for distribution networks connected to external grids with $X / R \geq 5$, no significant effect on the FTC is seen due to introduction of wind power. However, in a DS connected to grids with lower $\mathrm{X} / \mathrm{R}$ ratio wind power can affect the FTC significantly as wind power penetration increases.

An analysis is done to decrease the FTC using RPC from the wind turbines. Two types of DSs are considered: one connected to relatively strong $(\mathrm{SCC}=171 \mathrm{MVA}, \mathrm{X} / \mathrm{R}=10)$ external grid and the other to weak $(\mathrm{SCC}=80 \mathrm{MVA}, \mathrm{X} / \mathrm{R}=$ 1) external grid. The results show that RPC can be used to effectively reduce the FTC in both cases. However, the reactive power required to reduce the FTC by a specific percent depends on the SCC and the $\mathrm{X} / \mathrm{R}$ ratio. The reactive power requirement decreases with higher $\mathrm{SCC}$ and $\mathrm{X} / \mathrm{R}$ ratio.

A further investigation on RPC is carried out for wind farms located farther from the substation. However, the change in reactive power requirement and network loss is found to be only minor. Hence the RPC method is found to be effective even when wind farms are far away from the substation.

Finally the practical implementation of RPC to reduce the number of tap changes depends on the maintenance cost of the tap changers involved, the cost of reactive power from the wind turbines, and the change in power loss that occurs within the network due to RPC.

\section{ACKNOWLEDGMENT}

The authors would like to acknowledge Lars Ohlsson from Falbygdens Energi for providing network and measurement data.

\section{REFERENCES}

[1] M. Wang, A. Vandermaar, and K. Srivastava, "Review of condition assessment of power transformers in service," IEEE Electrical Insulation Magazine, vol. 18, no. 6, pp. 12 -25, Dec. 2002.

[2] J. Jagers, J. Khosa, P. D. Klerk, and C. Gaunt, "Transformer reliability and condition assessment in a south african utility," 2007.

[3] S. Tenbohlen, T. Stirl, G. Bastos, J. Baldauf, P. Mayer, M. Stach, B. Breitenbauch, and R. Huber, "Experienced-based evaluation of economic benefits of on-line monitoring systems for power transformers," CIGRE Session 2002, 2002.

[4] M. Minhas, J. Reynders, and P. de Klerk, "Failures in power system transformers and appropriate monitoring techniques," in High Voltage Engineering, 1999. Eleventh International Symposium on (Conf. Publ. No. 467), vol. 1, 1999, pp. 94 -97 vol.1.

[5] C. W. G. 05, "An international survey on failures in large power transformers in service," Electra, no. 88, pp. $21-47,1983$.

[6] R. Jongen, P. Morshuis, J. Smit, A. Janssen, and E. Gulski, "A statistical approach to processing power transformer failure data," in Cired 19th International Conference on Electricity Distribution, 2007.

[7] H.-U. Schellhase, R. Pollock, A. Rao, E. Korolenko, and B. Ward, "Load tap changers: investigations of contacts, contact wear and contact coking," in Proceedings of the Forty-Eighth IEEE Holm Conference on Electrical Contacts, 2002, 2002, pp. $259-272$.

[8] J. Erbrink, E. Gulski, P. Seitz, and R. Leich, "Advanced on-site diagnosis of transformer on-load tap changer," in Electrical Insulation, 2008. ISEI 2008. Conference Record of the 2008 IEEE International Symposium on, june 2008, pp. $252-256$.
[9] P. Kang and D. Birtwhistle, "On-line condition monitoring of tap changers-field experience," in Electricity Distribution, 2001. Part 1: Contributions. CIRED. 16th International Conference and Exhibition on (IEE Conf. Publ No. 482), vol. 1, 2001, p. 5 pp. vol.1.

[10] M. Foata, C. Rajotte, and A. Jolicoeur, "On-load tap changer reliability and maintenance strategy," Paris, 2006.

[11] M. Redfern and W. Handley, "Duty based maintenance for on-load transformer tap changers," in Power Engineering Society Summer Meeting, 2001 , vol. 3, 2001, pp. $1824-1829$ vol.3.

[12] P. Kang and D. Birtwhistle, "Condition assessment of power transformer onload tap changers using wavelet analysis and self-organizing map: field evaluation," IEEE Transactions on Power Delivery, vol. 18, no. 1, pp. 78 - 84, Jan. 2003.

[13] B. Handley, M. Redfern, and S. White, "On load tap-changer conditioned based maintenance," Generation, Transmission and Distribution, IEE Proceedings-, vol. 148, no. 4, pp. 296 -300, Jul. 2001.

[14] E. G. Romero, "Voltage control in a medium voltage system with distributed wind power generation," Master thesis, Lund University, Lund, 2007.

[15] P. Carvalho, P. Correia, and L. Ferreira, "Distributed reactive power generation control for voltage rise mitigation in distribution networks," Power Systems, IEEE Transactions on, vol. 23, no. 2, pp. $766-772$, may 2008.

[16] D. S. Romero, "Voltage regulation in distribution systems - tap changer and wind power," Master thesis, Lund University, Lund, 2010.

[17] S. Baghsorkhi and I. Hiskens, "Impact of wind power variability on subtransmission networks," in Proceedings of the IEEE Power and Energy Society General Meeting, July 2012.

[18] H. Saadat, power system analysis. PSA publishings, 2010.

[19] A. Wächter and L. T. Biegler, "On the implementation of an interiorpoint filter line-search algorithm for large-scale nonlinear programming," Mathematical Programming, vol. 106, pp. 25-57, 2006.

[20] P. Chen, "Stochastic modeling and analysis of power system with renewable generation," $\mathrm{PhD}$ thesis, Aalborg university, Aalborg, Jan. 2010.

[21] B. Singh and S. Singh, "Wind power interconnection into the power system: A review of grid code requirements," The Electricity Journal, vol. 22, no. 5, pp. $54-63,2009$.

Shemsedin Nursebo Salih was born on March 10, 1983 in Ethiopia. He studied his B.Sc. in electrical engineering at Arba Minch University, Ethiopia. He did his M.Sc. in power engineering at Chalmers university of Technology, Sweden, from where he graduated in 2010. Now he is doing his $\mathrm{PhD}$ degree at Chalmers University of technology. His research area is wind power integration in distribution system.

Peiyuan Chen (S'2007, M'2010) received his B.Eng. degree in Electrical Engineering from Zhejiang University, China, in 2004, M.Sc. degree in Electric Power Engineering from Chalmers University of Technology, Sweden, in 2006, and PhD degree in Stochastic Modelling and Analysis of Power System with Renewable Generation from Aalborg University, Denmark, in 2010. Currently, he is assistant professor at Chalmers University of Technology. His main research interests are optimal operation and planning of power system with integration of wind power.

Ola Carlson was born in Onsala, Sweden in 1955. He received the M.Sc. and Ph.D. degree in Electrical Engineering from Chalmers University of Technology, Gothenburg, Sweden in 1980 and 1988, respectively. He is currently a Professor in sustainable power production at the Department of Energy and Environment at Chalmers University of Technology. He had three years of industry experience in the areas of variable speed systems for wind turbines. His major interests are electrical systems for renewable energy and hybrid electric vehicles. 